\title{
Psychiatric Comorbidities in Patients with Deliberate Self-Harm in a Tertiary Care Center
}

\author{
Subash Ghimire,' Sagar Devkota,' Rasmita Budhathoki, 'Akhilesh Thakur, 'Nidesh Sapkota'
}

'B. P. Koirala Institute of Health Sciences, Dharan, Nepal.

\begin{abstract}
Introduction: Deliberate self-harm (DSH) is one of the common psychiatric emergencies in medical practice. It has become a global health problem with rates increasing over time. Very few studies have been conducted on this important health issue in Nepal. We conducted a hospital based study to evaluate the cause, mode and psychiatric comorbidities present in patients of DSH. Methods: This cross sectional study was performed on 200 cases of deliberate self-harm in a tertiary referral centre in Eastern Nepal from April 2012 to July 2012 by the data collected from the medical records of these patients. Various sociodemographic data and psychiatric comorbidities prevalent in them were studied. Results: Most of the patients (77\%) were below the age of 35 . The female-to-male ratio was $1.35: 1.76 \%$ of the patients had received formal education. Majority $(73.5 \%)$ were married. By occupation, 38\% were housewives and $25.5 \%$ were students. $72.5 \%$ of cases had consumed organophosphates/-chlorides. Interpersonal conflict (72\%) was the major cause for DSH. Psychiatric disorders according to ICD-10 criteria were found in 37\% of cases and premorbid personality problems were found in $20 \%$ of cases. The most prevalent psychiatric disorder was adjustment disorder $(13.5 \%)$ followed by mood disorder (11\%). Conclusion: Majority of DSH cases were of younger generation. Psychiatric disorders and comorbid personality problems were commonly seen in DSH patients. This has significance for proper evaluation and management.
\end{abstract}

Keywords: deliberate self-harm; organophosphorous; para suicide; psychiatric co-morbidities.

\section{INTRODUCTION}

Deliberate self-harm (DSH) is one of the common psychiatric emergencies in medical practice. ${ }^{1}$ According to World Health Organization, deliberate self-harm is "An act with a non-fatal outcome in which an individual deliberately initiates a non-habitual behaviour that, without intervention from others, will cause self-harm, or deliberately ingest a substance in excess of the prescribed or generally recognized therapeutic dosage, and which is aimed at realizing changes which the subject desired, via the actual or expected physical consequence". ${ }^{2}$

$\mathrm{DSH}$ is associated with higher risk of suicide in future. ${ }^{3}$ Researches conducted in several countries worldwide have reported increasing rates of psychiatric disorders. $^{4-6}$ The increasing number of cases of DSH makes it a challenging health-issue. ${ }^{7}$ It has become a major social problem in India at a rate of $9.74 \%$ per 100,000 population. ${ }^{8}$ Sri Lanka leads among countries of South Asia with the reported incidence of 3.7/100000 population a year. ${ }^{9}$ Other studies in Indian sub-continent that have focussed on various factors related to suicides shows that prevalence of DSH is increasing every year. ${ }^{10,11}$ Thapa et al, in the Lalitpur district of Nepal have shown the suicide rate of $3.7 / 100000$ population/ year. ${ }^{12}$ Co-morbidities of psychiatric disorder has been 
found common in various studies..$^{4,5}$

There are very few studies in Nepal conducted to understand the relation between the cases of DSH and the psychiatric co-morbidities. ${ }^{12}$ We conducted this study to (i) understand the socio-demographic variables in deliberate self-harm patients (ii) find the modes and precipitating cause (iii) look for the prevalence of psychiatric and personality disorders in deliberate-self harm patients.

\section{METHODS}

This cross sectional study was carried out in B. P. Koirala Institute of Health Sciences (BPKIHS) - a tertiary referral centre situated in Eastern part of Nepal. A total of 200 patients who had attended emergency department of BPKIHS in between April 2012 and July 2012 were studied by the data collected from the medical records of these patients. Variables related to socio-demographic distribution, family background, suicide characteristics were assessed using a self-designed proforma. All patients had been interviewed after stabilization, by a psychiatrist who collected information from the patient's relatives, friends, witnesses and past medical records. Medical data were collected with respect to socio-demographic variables, mode of $\mathrm{DSH}$, duration of medical access, premorbid personality, cause of DSH and psychiatric co-morbidities.

\section{RESULTS}

Out of the total 200 cases studied, 115 (57.5\%) were female and $85(42.5 \%)$ were male. The female to male ratio was $1.35: 1$. The mean age was $27 \pm 10.76$ years. One hundred fifty four patients (77\%) were below 35 years of age (Table 1 ).

\begin{tabular}{|lll|}
\hline \multicolumn{3}{|l|}{ Table 1. Age distribution. } \\
\hline Age group & No. & $\%$ \\
$15-24$ & 107 & 53.5 \\
$45-34$ & 47 & 23.5 \\
$35-44$ & 22 & 11 \\
$45-54$ & 18 & 9 \\
55 \& above & 06 & 3 \\
Total & 200 & $100 \%$ \\
\hline
\end{tabular}

One hundred fifty two $(76 \%)$ had received formal education while $17(8.5 \%)$ were uneducated. One hundred forty seven $(73.5 \%)$ were married and 50 $(25 \%)$ were unmarried (Table 2$)$. Seventy six patients $(38 \%)$ were housewives by occupation and $51,25.5 \%$, were students (Table 3 ).

\begin{tabular}{|lll|}
\hline Table 2. Marital status & & \\
\hline Status & No. & $\%$ \\
Married & 147 & 73.5 \\
Unmarried & 50 & 25 \\
Divorced/ married but & 3 & 1.5 \\
living separately & 200 & 100 \\
Total & 200 \\
\hline
\end{tabular}

\begin{tabular}{|lll|}
\hline \multicolumn{2}{|l|}{ Table 3. Occupational status. } \\
\hline Occupation & No. & $\%$ \\
Housewife & 76 & 38 \\
Student & 51 & 25.5 \\
Farmer & 13 & 6.5 \\
Unemployed & 7 & 3.5 \\
Teacher & 3 & 1.5 \\
Others & 50 & 25 \\
Total & 200 & 100 \\
\hline
\end{tabular}

Majority of the patients were Hindus, 190, followed by Buddhists (6) and Muslims (4). Consumption of Organophosphate and organochlorine compounds, 145 $(72.5 \%)$, was the most common mode of DSH followed by zinc phosphide, 19 (9.5\%), and paracetamol, 6 (3\%). Ten patients $(5 \%)$ were found using other compounds like phenol, copper sulphate, dhatura, etc., (Figure 1). Of the 200 patients, 160 (80\%) patients were well adjusted. Forty patients (20\%) had some premorbid problems like emotionally unstable, antisocial, obsessive compulsive, etc., (Table 4).

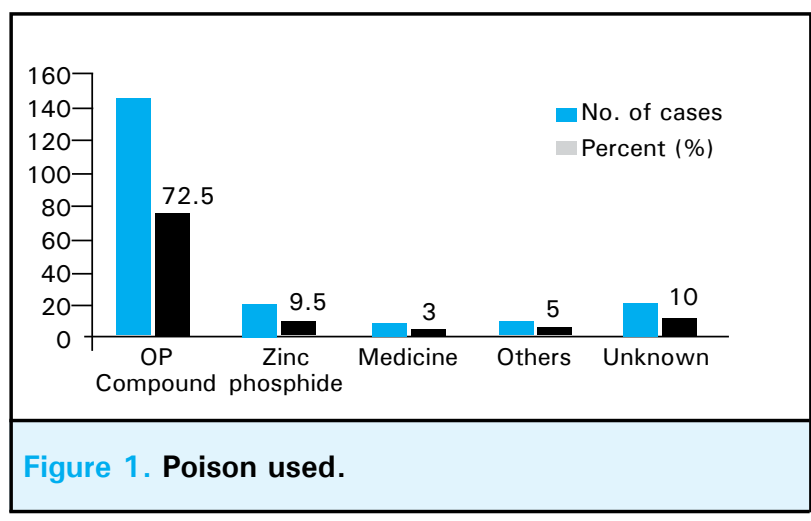

\begin{tabular}{|lll|}
\hline \multicolumn{2}{|l|}{ Table 4. Premorbid personality. } \\
\hline Premorbid personality & No. & $\%$ \\
Well adjusted & 160 & 80 \\
Not well adjusted & 40 & 20 \\
Total & 200 & 100 \\
\hline
\end{tabular}

Interpersonal conflict accounted for majority of the causes, 144 (72\%), followed by marital conflicts, 29 $(14.5 \%)$, and failure in relationship-love affair/romantic relationship, seven $(3.5 \%)$. Psychiatric disorder was 
the primary cause of DSH in $10(5 \%)$ cases (Figure 2). Psychiatric co-morbidities were present in 74 (37\%) cases. Out of these, majority had Adjustment Disorder, 27, followed by Mood Disorder, 22. Substance related disorder was present in 14 cases (Figure 3).
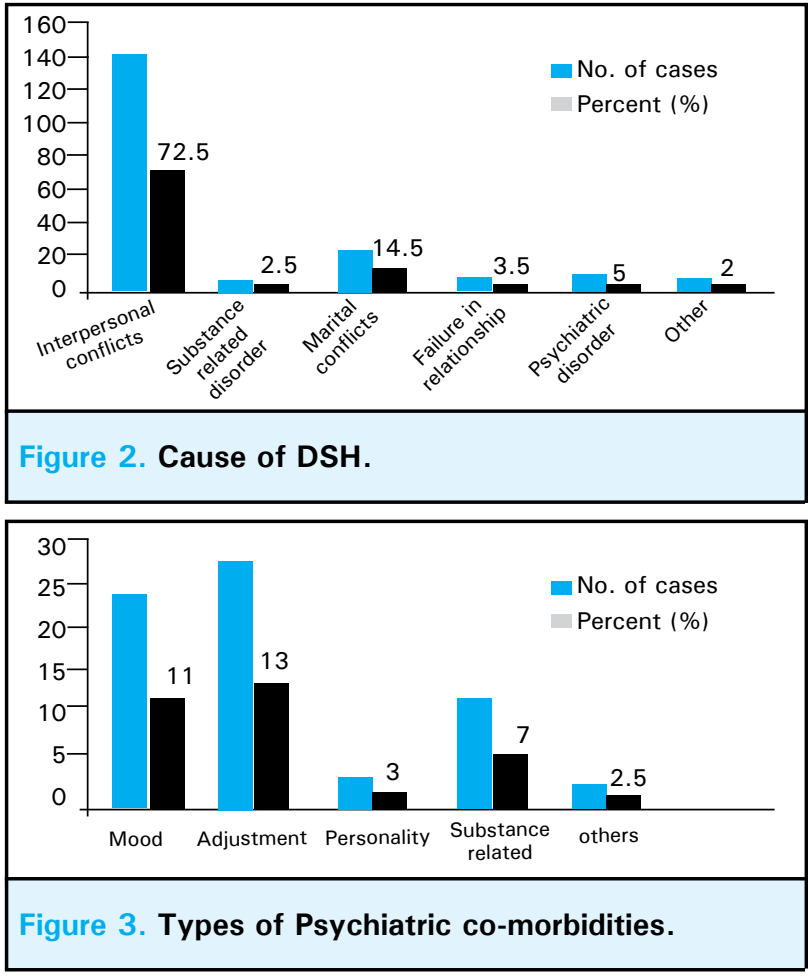

\section{DISCUSSION}

In our study, the most common age group attempting suicide among both sexes was 15-24 years followed by 25-34 years. These two groups constituted $77 \%$ of the total patients. The mean age was $27 \pm 10.76$ years. These findings are comparable with most of the Indian literatures. ${ }^{13,14}$ Previous studies done in BPKIHS ${ }^{15}$ and other hospitals of Nepal also revealed similar findings. ${ }^{16,17}$ However, this contrasts with research of western literature, where older age groups are the most affected. ${ }^{18}$ Researches by Sobhani et al, $^{19}$ in Northern Iran, Sato et al, ${ }^{20}$ in Japan also have reported $\mathrm{DSH}$ being more common in the elderly.

In this study, females were found to be more vulnerable to $\mathrm{DSH}$ than males. The $\mathrm{F}: \mathrm{M}$ ratio was $1.35: 1$; similar to those reported by other studies done in Nepal. ${ }^{15,17,21}$ But this finding is in contrast with the studies done in India ${ }^{13,14,16}$ that show male predominance. However several studies have also found to be gender neutral. ${ }^{23,24}$ The female population being higher in our study might be due to their number in the sample itself. Also, females are more exposed to the daily stress and strain of the society. Furthermore, this study has reviewed only the cases of DSH with ingestion of compounds and it is known that females are known to choose less violent modes $^{9}$ for DSH. Also this is a hospital based study and no community studies are available so far on the prevalence and gender difference of DSH in Nepal for comparison.

In our study, $76 \%$ received formal education, $15 \%$ received informal education and $8.5 \%$ were uneducated. Studies done in Kathmandu University Teaching Hospital ${ }^{21}$ and India ${ }^{13}$ show similar results. Failure in life and tolerance to problems is better understood by literates plus they are more subjected to competitive world than the illiterate. This makes them more vulnerable to $\mathrm{DSH}$.

This study has shown that DSH is more common in married (73.5\%) than unmarried/divorced. This contradicts previous studies done in BPKIHS. ${ }^{15}$ However, similar findings have been reported by Shukla et $\mathrm{al}^{10}{ }^{10}$ in India. This shows that in our part of world family dispute/ stress has a huge impact on the smooth functioning of the family as well as the society.

In this study, majority of the patients were housewives (38\%), followed by students $(25.5 \%)$ and labour $(11 \%)$. This finding varies with that of some previous studies in BPKIHS ${ }^{15}$ and India ${ }^{25}$ where students were the most vulnerable group. Despite vigorous efforts towards gender equity and female empowerment, females still remain the major stress-bearers exposing them more to interpersonal problems with parents, in-laws, spouse and other family members which could be the major contributor for the predominance of DSH among the house-wives.

Consumption of Organophosphates (OP) and -chlorides compound $(72.5 \%)$ was the most common mode of DSH in our study, which was followed by Zinc Phosphide $(9.5 \%)$ and Paracetamol $(5 \%)$. Majority of the population of Nepal earn their living by agriculture. So, there is always an easy access to insecticides and pesticides which allows them to be commonly used as a mode of DSH. These findings are consistent with studies conducted in $\mathrm{Nepal}^{21}$ and other countries. ${ }^{25,26}$ Another study in Dharan showed that $62 \%$ had used OP. ${ }^{22}$

We found that $80 \%$ of the patients were well adjusted and $20 \%$ had some premorbid personality disorder like emotionally unstable, antisocial, and anxious. However, a much higher prevalence $(40-50 \%)$ has been seen in studies by Suomian et $\mathrm{al}^{4}{ }^{4}$ and Ferreria de Casto et al. ${ }^{5}$ Personality disorder acts as root of suicidal behaviours. It acts in many ways by making people vulnerable to major psychiatric disorders such as depression or alcoholism, by setting up unwanted life events, producing problems in relationship and social adjustment, by subtracting the capability to handle a 
psychiatric or physical disorder and by pulling a person into conflicts with family members and other people.

In our study, interpersonal conflicts $(72 \%)$ and marital conflicts $(14.5 \%)$ were found to be the major causes of $\mathrm{DSH}$. This is in contrast to the findings of Ponnudurai et al, ${ }^{12}$ in India and Dieserud et al, in Norway. ${ }^{27}$

Based on the ICD-10 criteria, the prevalence of the psychiatric disorders in our study was $37 \%$. This is far less than some of the western studies which have reported comorbid psychiatric disorders in $85-89 \%$ of DSH patients. ${ }^{5}$ However some Indian literature report even lesser numbers (3.5) \%. ${ }^{28}$ Major psychiatric disorders found were adjustment disorder (13.5\%) followed by mood (11\%) and substance related disorder (7\%). Of the 14 patients diagnosed with alcohol dependence syndrome, all of them were male and attempted suicide in intoxicated state. A higher rate of adjustment disorder probably is the reflection of sociocultural milieu. Similar rates were reported by studies in India. ${ }^{14,29}$ These findings are in contrast to those observed by Sapkota et $\mathrm{al}^{15}$ and Vajda et $\mathrm{al}^{130}$ where mood disorder was predominant.

Many of the DSH cases are under-reported due to various reasons. One of the major reasons for this is the fact that DSH is considered a social stigma in our part of world due to which most of the cases present as accidental poisoning. This can lead to an exaggerated number of accidental poisoning. ${ }^{31}$ Patients with DSH have high rates of psychiatric illness present in them and therefore need to be carefully screened for psychiatric problems. Studies cited above including this shows that $\mathrm{DSH}$ is high in younger generation. So, special programs must be implemented by the government regarding awareness on DSH targeting this generation.

Accessibility and availability of insecticides and pesticides to authorized persons only and restricted sales with legal implications may help in decreasing the incidence of DSH. The rampant and haphazard use of medicines by pharmacies without prescriptions should be discouraged. Moreover, early identifications of suicide prone individuals, rehabilitation measures and family referral are strongly suggested. There should be relevant programs to make all the responsible authorities aware about this problem. DSH help-lines and strict laws related to suicide must be made.

A lot of DSH patients have comorbid disorders and they need an integrated care package involving multiple agencies. Alcohol related problems and hence require proper assessment and care.

\section{LIMITATIONS}

Being a hospital-based study, it may not have represented the entire population and may also have presented a greater number of patients of DSH with comorbid psychiatric conditions as people with DSH who don't seek medical attention may have been missed.

This study has taken into account DSH by ingestion of compounds only. So, other methods like hanging, jumping from height, and injury by sharp objects, drowning, etc., were not observed.

The socio-economic status and the financial burden may have been over-looked in this study.

\section{CONCLUSIONS}

Majority of the patients with DSH belonged to the younger generation. Psychiatric comorbidities were found in many of them. So, it is of utmost importance to raise public awareness towards early detection and prompt treatment of the DSH patients. Further, people should be made aware that psychiatric disorders are treatable and with proper treatment and care, these patients can lead a healthy life. Restriction of easy availability of highly toxic pesticides can greatly reduce the number of attempters. Over-the-counter availability of the psychotropic medicines which can be easily used for DSH should be discouraged. Strict laws must be formulated and implemented right from the grass root level. Potentially poisonous medicines must not be sold without prescription from a Registered Medical Practitioner.

\section{REFERENCES}

1. Bennewith OM, Sharp D, Gunnell D, Peters TJ, Stocks N. Deliberate self harm is common reason for emergency medical admission. BMJ 2001;322:1065

2. World Health Organization (1986). Working Group on Preventive Practices in Suicide and Attempted Suicide. Copenhagen, WHO Regional Office for Europe.
3. Hawton K, Fagg J. Suicide and other causes of death, following attempted suicide. British Journal of Psychiatry 1988;152:359-66.

4. Suominen K, Isometsa E, Henriksson M, et al. Consultation versus research diagnoses of mental disorders among suicide attempters. Nordic Journal of Psychiatry 1999;53:253-56. 
5. Ferreira de Castro E, Cunha M, Pimenta F, et al. Parasuicide and mental disorders. ActaPsychiatricaScandinavica 1998;97:25-31.

6. Foster T, Gillespie K, McClelland R. Mental disorders and suicide in Northern Ireland. British Journal of Psychiatry 1997;170:447-52.

7. Weissman M M. The epidemiology of suicide attempts. Archives of General Psychiatry 1974;30:737-46.

8. Government of India (1994) Accidental deaths \& suicide in India, National crimes records Bureau, New Delhi: Ministry of home affairs.

9. Roy A. Suicide. In : Kaplan and Sadock's Comprehensive Text of Psychiatry, vol.11, 7th edition Lippincott Wilkins 2000.p.2031-2040.

10. Shukla G D, Varma B L, Mishra D N. Suicide in Jhansi city. Indian Journal of Psychiatry 1990;32:44-52.

11. Ponnudurai R, Jayakar J. Attempted suicide in Madras. Indian Journal of Psychiatry 1986;28:59-62.

12. Thapa B \&Carlough M C. Suicide Incidence in the Lalitpur District of Central Nepal. Tropical doctor 2000;30:200-3.

13. Rao K N, Kulkarni RR, Begum S. Comorbidity of psychiatric and personality disorders in first suicide attempters. Indian J Psychol Med 2013;35:75-9.

14. Shailaja S Patil, Mallikarjun C Yadavannavar, Chaukimath S P. Deliberate Self Harm and Psychiatric CoMorbidity: A Hospital Based Study. Asian J. Exp. Biol. Sci. 2011;2:367-71.

15. Sapkota $\mathrm{N}$ et al. Hundred psychiatric outpatients presented with attempted suicide. Health Renaissance 2011; Vol 9 (No.3):162-67.

16. P. K Kiran Kumar et al. Epidemiology of psychiatric disorders in deliberate self-harm victims. Journal of Evolution of Medical and Dental Sciences 2013;27:738-44.

17. Khadka SB, Ale SB. A study of poisoning cases in emergency Kathmandu Medical College Teaching Hospital. Kathmandu University Med J 2005;3:388-91.

18. Lonnqvist J K. Epidemiology and causes of suicide. In: Gelder et al's New oxford textbook of Psychiatry, vol 1, 1st edn, Oxford University Press; 2000.P.1033-1038.
19. Sobhani AR, Shojaii-Tehrani H, Nikpour E, Noroozi-Rad N. Drug and Chemical Poisoning in Northern Iran. Iranian Journal of Medical Sciences 2002;1:27.

20. Sato T, Takeichi M, Hara T. Suicide attempts by agricultural chemicals. Indian Journal of Psychiatry 1993;35:209-10.

21. Marahatta et al. poisoning cases attending emergency department in Dhulikhel Hospital- Kathmandu University Teaching Hospital. Kathmandu University Medical Journal 2009;7:152-56.

22. Singh DP, Acharya RP. Patterns of poisoning in Nepal. J Inst Med. 2006;28:3-6.

23. Stanley B, Gameroff MJ, Michalsen V, Mann JJ. Are suicide attempters who self-mutilate a unique population? Am J Psychiatry 2001;158:427-32.

24. Briere J, Gil E. Self-mutilation in clinical and general population samples: prevalence, correlates, and functions. Am J Orthopsychiatry 1998;68:609-20.

25. Gupta S C, Singh H. Psychiatric illness in suicide attempters. Indian Journal of Psychiatry 1981;23:69-74.

26. Phillips MR, Li X, Zhang Y. Suicide rates in China, 1995-99. Lancet 2002;359:835-40.

27. Dieserud G, Loeb M, Ekeberg O. Suicide behavior in the municipality of Baerum, Norway: A 12-year prospective study of parasuicide and suicide. Suicide Life Threat Behavior 2000;30:61-73.

28. Murthy, R.S. Urbanization and mental health. Indian J. Soc. Psychiatry 1993;9:16-9.

29. Gupta, B. \&Trzepacz, P. Serious overdosers admitted to a general hospital: comparison with nonoverdose self-injuries and medically ill patients with suicidal ideation.General Hospital Psychiatry 1997;19:209-15.

30. Vajda J et al. Factors associated with repeat suicide attempts among adolescents. Australian and New Zealand Journal of Psychiatry 2000;3:437-44.

31. Manian T. Suicide and parasuicide in a hill Resort of Malaysia. British J of Psychiatry 1998;153:222-25. 